\title{
ДОШКОЛЬНАЯ ПЕДАГОГИКА
}

УДК $373.24+316.6$

DOI 10.23951/1609-624X-2018-7-96-102

\section{ХАРАКТЕРИСТИКА РЕЧЕВОЙ АКТИВНОСТИ ДЕТЕЙ СТАРШЕГО ДОШКОЛЬНОГО ВОЗРАСТА С РАЗЛИЧНЫМ СОЦИОМЕТРИЧЕСКИМ СТАТУСОМ}

\author{
А. Н. Пронина, И. В. Яковлева
}

Елеикий государственный университет им. И. А. Бунина, Липецкая область, Елеи

\begin{abstract}
Рассматривается вопрос о сравнительных характеристиках речевой активности детей старшего дошкольного возраста с различными социометрическими статусами. Представлено описание критериев, показателей и уровней речевой активности детей дошкольного возраста, которые используются при организации наблюдений за детьми различных социометрических статусов в свободной игровой и организованной совместной деятельности. Например, выявлен высокий уровень речевой активности у детей со статусом «звезда», средний и низкий уровень речевой активности у детей с неблагоприятными социометрическими статусами. Дано подробное описание уровней и характеристик речевой активности детей старшего дошкольного возраста с различными социометрическими статусами. Представлены статистика сравнения критериев, уровней речевой активности детей с различными социометрическими статусами и объяснение таких различий. Так, в результате проведенного исследования выявлены различия между детьми со статусами «звезды» и «изолированные» по критериям речевой инициативности, мотивации и типов речевой коммуникации.
\end{abstract}

Ключевые слова: речь, активность, речевая активность, сочиализачия, межличностные отночения, соииометрический статус, дошкольники, влияние, группа сверстников.

Развитие речи является наиболее значимым достижением онтогенетического развития ребенка. Речь выступает основным средством познания окружающего мира, освоения социокультурного опыта, общения и взаимодействия дошкольника с социальным окружением. С помощью речи ребенок становится полноправным партнером по социальному взаимодействию с окружающими людьми. Смена на протяжении онтогенеза различных форм общения (ситуативно-личностная, ситуативно-деловая, внеситуативно-познавательная, внеситуативно-личностная) способствует переходу от познания предметного мира к социальному миру людей, благодаря чему ребенок устанавливает межличностные отношения со взрослыми и сверстниками и с помощью речи осваивает сферу социальных отношений.

Сверстники для ребенка в старшем дошкольном возрасте становятся предпочтительными партнерами по сравнению со взрослым. Посредством речи дошкольник стремится привлечь внимание партнера-сверстника по взаимодействию, вовлечь его в сотрудничество, выразить соответствующее отношение к сверстнику, получить одобрение и подтверждение своих действий, достижений. Речевое общение приводит к возникновению у дошкольников избирательных привязанностей между детьми.

Но для того, чтобы речь детей выполняла свои социальные функции по установлению межличностных взаимоотношений со сверстниками, необходимо, чтобы она была мотивированной, инициа- тивной, динамичной, содержательной, эмоционально-выразительной, соответствующей конкретной ситуации. Данные критерии относятся к характеристикам речевой активности.

Статистические данные фиксируют снижение речевой активности детей старшего дошкольного возраста: преобладание пассивности и снижение инициативности в общении, отсутствие речевой мотивации, эмоционально невыразительная речь, недостаточная целенаправленность речи. Среди факторов снижения речевой активности дошкольников можно назвать обеднение окружающей языковой среды, культуры речи, преобладание информационных технологий общения над непосредственным, недостаточным вниманием родителей и воспитателей к проблемам речевого развития детей.

Различные исследователи в области психологии и лингвистики (Л. С. Выготский [1], И. А. Зимняя [2], А. Н. Леонтьев [3], А. М. Шахнарович [4] и др.) рассматривают социальный характер речевой деятельности. Ж. Пиаже [5] выделяет две группы речи детей в ходе диалога - эгоцентрическую и социализированную речь. Социализированная речь в процессе диалога включает в себя отражение таких элементов децентрации, как критика, приказания, просьбы, вопросы, угрозы, ответы, которые обеспечивают функцию социализации детей.

Т. Б. Филичева [6], классифицируя функции речи на выражение, сообщение, обозначение, воздействие, раскрывает ее социальный характер и направ- 
ленность на обеспечение процесса социализации посредством выражения своего отношения к соблюдению или нарушению сверстниками социально значимых норм, обмену информацией с другими людьми, обозначению с помощью речи социальных действий, правил и словесному регулированию.

Теоретический анализ психологической литературы по проблеме межличностных отношений детей дошкольного возраста (О. А. Смирнова [7], М. А. Репина, Т. К. Мухина [8], М. Poteat, M. Ironsmith, J. Bullock [9], D. Nelson, K. Burner, S. Coyne, C. Hart, C. Robinson [10] и др.) позволил выявить, что в основе установления избирательных привязанностей и дружеских отношений лежит инициативность, потребность в общении и признании сверстников, признание взрослого, способность удовлетворить коммуникативные потребности ровесников, которые реализуются посредством проявления различных аспектов речевой активности.

Речевая активность детей дошкольного возраста представлена в науке изучением различных аспектов данной проблематики: мотивации речевой деятельности (А. В. Колосовская [11]); причинам речевой пассивности детей (Е. Крутий [12]); формирования связности речи старших дошкольников (О. С. Ушакова [13]). Исследования различных авторов позволили разработать следующие разноплановые определения речевой активности: быстрые речевые реакции в диалоге, быстрый выбор слов, интенсивное построение фразы (В. Г. Горецкий [14]), повторность употребления языковых средств в меняющихся условиях, включающую не только говорение, но и слушание, восприятие речи (М. М. Алексеева, В. И. Яшина [15]), степень участия детей в порождении различных разновидностей высказываний на уроке (Т. А. Ладыженская, Т. И. Тамбовкина [16]), выделение, вычленение детьми элементов речи, включающее определение составления речевого высказывания как цели своей деятельности, элементарной структуры высказывания разных речевых жанров, отбор доступных языковых средств для его оформления и самоконтроль за ходом его реализации (Л. В. Красильникова [17]). В работах различных авторов (О. А. Смирнова, М. А. Репина, Т. К. Мухина и др.) имеются некоторые высказывания о том, что речевая активность выступает фактором, который влияет на взаимоотношения и положение детей в коллективе сверстников.

Без проведения эксперимента по выявлению характеристики речевой активности детей различного социометрического статуса в группе детей дошкольного возраста невозможно установить, какие именно проявления речевой активности обеспечивают ребенку соответствующее положение в детском коллективе.
Цель эксперимента - выявление характеристик речевой активности детей старшего дошкольного возраста с различными социометрическими статусами.

Задачи исследования:

- установить социометрический статус детей в группе сверстников;

выявить уровень речевой активности детей дошкольного возраста;

- сравнить критерии, показатели и уровни речевой активности детей с различными социометрическими статусами.

Авторы предположили, что речевая активность детей с благоприятными статусами будет значительно отличаться по различным критериям от речевой активности детей с неблагоприятными статусами. Речевая пассивность будет характерна для детей с социометрическими статусами «непринятые» и «изолированные».

Исследование проводилось в 2017 г. В эмпирическом исследовании принимали участие дети старшего дошкольного возраста дошкольных образовательных организаций Липецкой области (188 детей). Средний возраст участников - $(6,50 \pm 0,32)$ года. Разброс возраста: $\min -6, \max -7$ лет.

Исследование проходило в три этапа. На первом этапе изучали социометрическое положение детей в группе сверстников посредством методики «Секрет», направленной на выявление социометрического статуса ребенка (Я. Л. Коломинский [18]).

Второй этап включал диагностику проявлений речевой активности детей старшего дошкольного возраста. Основной методикой выступило наблюдение за речевым общением детей в свободной игровой и организованной групповой совместной деятельности детей (коллективном рисовании).

На третьем этапе выявлялись различия критериев речевой активности у детей разных социометрических статусов с помощью параметрического $t$-критерия Стьюдента, используя программу SPSS Statistics.

Так как на данный момент отсутствуют критерии, показатели и уровни речевой активности детей дошкольного возраста, авторами были разработаны собственные критерии и уровни оценки речевой активности. В качестве критериев оценки речевой активности детей старшего дошкольного возраста выступили следующие:

- инициативность (соотношение обращенной (инициативной) и ответной речи; соотношение речевых инициатив в виде вопросов и даваемых ответов);

- типы речевой коммуникации (соотношение диалогической и монологической речи, соотношение говорения и слушания); 
- речевая мотивация (использование речи для стимулирования и побуждения других детей к действиям, организации совместной деятельности, к удовлетворению потребности передавать, получать информацию);

- содержательность речи (информационная насыщенности речи, ее точность, соответствие конкретной ситуации);

- эмоциональная выразительность речи (употребление эмоциональной лексики, образных средств, средств эмоциональной выразительности речи для привлечения к собственным действиям, личностным качествам, проблемам, собственным достижениям, проявление отношения к сверстнику, его действиям, поступкам, проблемам, его достижениям).

Показателями вышеизложенных критериев выступили самостоятельность, частота проявления, скорость, четкость. Проявление критериев и показателей фиксировалось в баллах (3 балла - проявляет самостоятельно и постоянно, 2 балла - проявляет с некоторой помощью, в некоторых ситуациях, 1 балл - требуется значительная помощь, проявляет редко, 0 баллов - не проявляет). В соответствии с данными критериями и показателями были выделены следующие уровни сформированности речевой активности детей старшего дошкольного возраста:

- высокий - ребенок постоянно проявляет речевую инициативу в организации общения в виде различных вопросов к партнеру, обращается к нему с предложениями вариантов игры, действий, быстро и четко отвечает, использует различные типы высказываний (описаний, рассуждений); самостоятельно применяет различные речевые средства для получения недостающей информации, проявляет желание делиться с партнерами информацией, использует речь для регулирования с ними действий в процессе деятельности; в соответствии с конкретной речевой ситуацией использует как диалоговые, так и монологовые формы общения, часто говорит и рассказывает другим и также внимательно слушает партнеров; речь содержит разнообразную точную содержательно-насыщенную информацию, касающуюся организации деятельности с партнерами, достижения согласованности действий со сверстниками, разрешения конфликтных ситуаций; в речи постоянно присутствуют элементы эмоциональной лексики, образные средства, которые направлены на выражение собственного отношения к партнеру, его действиям, результату, процессу или на привлечение внимания к себе, своим действиям, своим достижениям;

- средний: ребенок лишь в некоторых ситуациях проявляет речевую инициативу в организации общения в виде различных вопросов, предложений к партнеру, не всегда быстро и четко отвечает, не всегда использует различные типы высказываний; требуется некоторая помощь в применении различных речевых средств для получения недостающей информации, самостоятельно не проявляет желания делиться с партнерами информацией, нечасто использует речь для регулирования с ними действий; диалоговые и монологовые формы общения иногда применяются не в соответствии с речевой ситуацией, часто говорит сам и в некоторых случаях невнимательно слушает партнеров; не во всех ситуациях речь содержательно-насыщенная и точная, может не использоваться для организации деятельности с партнерами, достижения согласованности действий со сверстниками, разрешения конфликтных ситуаций; не всегда в речи присутствуют элементы эмоциональной лексики, образные средства, направленные на выражение собственного отношения к партнеру, его действиям, результату, процессу, часто используются для привлечения внимания к себе, своим действиям, своим достижениям;

- ребенок не проявляет инициативу в организации общения, ответные формы речи преобладают над инициативными, ответы нечеткие и отличаются повествовательным типом высказываний; с помощью взрослого пытается применять различные формы и речевые средства для получения недостающей информации, отсутствует самостоятельность в использовании речи для получения информации, часто проявляется дисбаланс между диалогом и монологом, говорением и слушанием (много диалогов, но отсутствует монолог, много говорит сам и не слушает других либо наоборот), направленность речи только на получение информации для себя, необходимой для выполнения собственной деятельности, но не используется для организации действий с партнерами, речь содержательно бедна, неточная, не всегда соответствует конкретной речевой ситуации и ситуации общения; в речи редко используются элементы эмоциональной лексики, образные средства для выражения собственного отношения к партнеру, его действиям, проблемам или на привлечение внимания к себе, своим действиям, своим достижениям.

С помощью методики «Секрет» было выявлено, что в благоприятные социометрические статусные подгруппы вошли 59 \% детей от общей выборки, которые составили статус «звезды» - 29 \% и статус «принятые»- 30 \%. Неблагоприятные социометрические статусы распределились следующим образом: «непринятые» - 26 \% детей и «изолированные» $-15 \%$.

Наблюдение за речевой активностью детей в свободной игровой и организованной совместной деятельности позволило выявить ее различные проявления. Дети-«звезды» наиболее часто проявляют речевую инициативность, обращаются к другим детям с просьбами и предложениями органи- 
зовать игру, используют речь для распределения обязанностей, оказания соответствующей помощи, задают много вопросов другим детям для выяснения мнения других детей, много отвечают другим детям.

Дошкольники со статусами «принятые» и «непринятые» охотно проявляют речевую инициативность, но в тех случаях, например, когда им хочется привлечь к себе внимание партнеров-«звезд»и показать свои достоинства и преимущества в обладании той или иной игровой ролью, показать себя как удобного партнера. Они задают вопросы только по необходимости, когда нужно получить согласие, например, на выбор игрового оборудования или подтверждение правильности и точности реализации сюжета от детей-инициаторов с более высоким статусом. Ответная форма у таких детей преобладает над вопросами.

«Изолированные» дети часто проявляют инициативу в речи в форме вопросов, которые адресованы детям-организаторам с высоким статусом, и используются они в основном для описания своих способностей и возможностей, которые, как им кажется, могут пригодиться (понадобятся) другим детям в совместной игре или деятельности. Если «изолированных» детей принимают в игру, то у них повышается речевая инициативность как в виде вопросов, так и ответной формы, обусловленных желанием угодить детям, которые их приняли.

Дети со статусом «звезды» с активностью вступают в диалог с другими детьми, спрашивают у них, много рассказывают и объясняют другим детям (например, сюжет, правила игры), но с нежеланием слушают других детей, у них в большей степени преобладает монологическая речь.

У детей статусных подгрупп «принятые» и «непринятые» в равной степени проявляются диалогическая и монологическая речь, говорение и слушание. Они активно вступают в диалоги с другими детьми, особенно с детьми-организаторами «звездами», только в тех случаях, если от последних идет речевая инициатива в организации таких диалогов. Они могут также рассказывать и объяснять, если инициатива идет от других детей. В основном они являются хорошими слушателями, чем обеспечивают себе постоянство и успешность участия в совместных видах деятельности.

У детей статусной подгруппы «изолированные» преобладает диалоговая речь, которая, по мнению авторов, обусловлена стремлением и потребностью наладить взаимные контакты с детьми других статусов и установить хорошие партнерские отношения с ними. Монологи используют редко, в основном слушают информацию и указания от других детей.

У детей-«звезд» зафиксирован высокий уровень речевой мотивации. Речь они используют как сред- ство удовлетворения своих потребностей в организации деятельности, общении, в реализации и сохранении своих лидирующих позиций, подавлении инициативы других детей, достижении успеха и передачи необходимой информации.

Выявлено, что в статусных подгруппах «принятые» и «непринятые» речь выступает только как средство удовлетворения потребности получать и передавать необходимую информацию и достигать полученных результатов.

Для «изолированных» детей характерен средний уровень речевой мотивации, так как речь они используют только в тех случаях, когда им нужно вступить в совместную игру или деятельность с другими детьми или передать в них необходимую информацию.

При оценке содержательности было установлено, что речь детей-«звезд» обладает информационной насыщенностью, передает много необходимой информации, которая обладает точностью и касается организации и хода конкретной игры или совместной деятельности (описание сюжета, ролей, атрибутов, распределения материалов, обязанностей и т. д.).

Дети со статусами «принятые» и «непринятые» демонстрируют средний уровень содержательности речи, так как они часто используют повторение информации, полученной от других детей, не дополняя ее своей информацией, в некоторых случаях она характеризуется краткостью, отсутствием детализированности.

«Изолированные» дети также демонстрируют средний уровень содержательности речи и в точности повторяют информацию, полученную от детей других социометрических статусов, с которыми они вступают во взаимодействие. Эта особенность содержательности речи данной категории детей объясняется стремлением и желанием детей быть «нужным» партнером и четко выполнить требования и указания тех детей, которые их приняли в игру или совместную деятельность.

Для статусной подгруппы «звезды» использование эмоциональной выразительности речи характерно только для привлечения внимания и описания сюжета игры, своих достоинств и преимуществ как ее организатора. По отношению к личностным особенностям детям других статусных подгрупп средства эмоциональной выразительности в речи применяются мало.

У детей статусных подгрупп «принятые» и «непринятые» речь редко обладает эмоциональной выразительностью, в основном они используют образные средства выразительности речи для описания и привлечения внимания к своим личностным качествам и особенностям, которые, по их мнению, являются необходимыми и привлекательными для 
других партнеров по игре или совместной продуктивной деятельности.

Речь детей подгруппы «изолированные» обладает эмоциональной выразительностью во всех ее аспектах. Для реализации желания быть принятым средства эмоциональной выразительности речи используются данной категорией детей как для выражения эмоционального отношения к качествам и личности, проблемам других детей с высоким социометрическим статусом, так и привлечения внимания к своим собственным качествам, способностям и возможностям.

Соотнесение социометрического статуса с уровнем речевой активности представлено в табл. 1.

Таблица 1

Прочентное соотночение сформированности уровней речевой активности у детей стармего дочкольного возраста с различными социометрическими статусами

\begin{tabular}{|l|c|c|c|}
\hline \multicolumn{1}{|c}{$\begin{array}{c}\text { Социометрический } \\
\text { статус (\%) }\end{array}$} & \multicolumn{3}{|c|}{ Уровень речевой активности, \% } \\
\cline { 2 - 4 } & Высокий & Средний & Низкий \\
\hline 3везды (29\%) & 19 & 10 & 8 \\
\hline Принятые (30\%) & 10 & 9 & 7 \\
\hline Непринятые $(26 \%)$ & 5 & 4 & 11 \\
\hline Изолированные $(15 \%)$ & 4 & 4 & 9 \\
\hline
\end{tabular}

Результаты табл. 1 позволяют сделать вывод о том, что для детей с благополучными социометрическими статусами характерны высокие уровни сформированности речевой активности.

C помощью $t$-критерия Стьюдента выявлены различия между критериями речевой активности у детей с разными социометрическими статусами (табл. 2).

Выявлены различия между критериями «инициативность», «типы речевой коммуникации» и «речевая мотивация» у детей с социометрическими статусами «звезды» и «изолированные». По мнению авторов, это обусловлено тем, что данные категории находятся в прямо противоположных показателях позиций проявления речевой активности. Вместе с тем имеются следующие различия. Если «звезды» проявляют речевую инициативность, обращенную к другим детям для привлечения их к организации игры или совместной дея- тельности, то изолированные дети проявляют речевую инициативность для привлечения внимания к своим особенностям и возможностям. Речевая инициативность детей подгруппы «изолированные» выступает средством демонстрации своих особенностей и возможностей.

Различия речевой мотивации детей статусов «звезды» и «изолированные» авторы объясняют тем, что если у первых речь применяется как средство удовлетворения потребности организовать игру и найти выгодных партнеров по игре, то дети со статусом «изолированные» используют речь для привлечения внимания к себе, демонстрации своих способностей и особенностей, а также сохранения позитивных отношений с участниками более высоких социометрических статусов.

Различия между типами речевой коммуникации детей подгрупп «звезды» и «изолированные» авторы видят в том, что если первые используют в большей степени монологическую речь для реализации своих организаторских способностей и проявления властных полномочий, то изолированные используют в основном диалогическую речь для удовлетворения ими недостающего общения и контактов с другими детьми.

Хочется отметить, что рассматривались характеристики речевой активности детей старшего дошкольного возраста только в рамках взаимодействия и общения с другими детьми группы с позиции реализации конкретного социометрического статуса. Данная статья и полученные результаты аккумулируют много вопросов: в чем причины проявления различных показателей и уровней речевой активности, какие факторы обусловливают такое проявление речевой активности, как соотносится уровень речевого развития детей с проявлениями конкретных показателей и др. В рамках только данного исследования и статьи невозможно ответить на данные вопросы, требуется более глубокое дальнейшее исследование речевой активности в русле других проблем речевого и социального развития детей дошкольного возраста, которые дадут разноплановые интересные и значимые для науки и практики результаты.

Таблица 2

Сравнение средних баллов проявления критериев речевой активности у детей с различным сочииометрическим статусом по t-критерию Стьюдента

\begin{tabular}{|l|c|c|c|c|c|}
\hline \multirow{2}{*}{$\begin{array}{c}\text { Социометрический статус } \\
\text { (общее количество баллов) }\end{array}$} & $\begin{array}{c}\text { Книциатив- } \\
\text { ность }\end{array}$ & $\begin{array}{c}\text { Типы речевой } \\
\text { коммуникации }\end{array}$ & $\begin{array}{c}\text { Речевая } \\
\text { мотивация }\end{array}$ & $\begin{array}{c}\text { Содержатель- } \\
\text { ность речи }\end{array}$ & $\begin{array}{c}\text { Эмоциональная } \\
\text { выразительность речи }\end{array}$ \\
\hline Звезды (15-13 баллов) & $14,7^{*}$ & $14,5^{*}$ & $14,4^{*}$ & 14,9 & 13 \\
\hline Принятые (10-12 баллов) & 11,4 & 10,9 & 11,2 & 10,1 & 8 \\
\hline Непринятые (7-9 баллов) & 7,8 & 8,9 & 8,6 & 11 \\
\hline Изолированные (5 баллов) & $4,3^{*}$ & $5^{*}$ & $4,6^{*}$ & 4,4 & 7,9 \\
\hline
\end{tabular}

* Выявленные достоверные различия при $p<0,05$. 


\title{
Список литературы
}

1. Выготский Л. С. Собрание сочинений: в 6 т. Т. 4: Детская психология / под ред. Д. Б. Эльконина. М.: Педагогика, 1984. 432 с.

2. Зимняя И. А. Психология обучения неродному языку. М.: Русский язык, 1989. С. 14-15.

3. Леонтьев А. А. Основы психолингвистики. М.: Смысл, 1997. С. 19.

4. Шахнарович А. М. Детская речь в зеркале психолингвистики. М.: ИЯз РАН, 1999. С. 34-36.

5. Пиаже Ж. Речь и мышление ребенка. СПб.: Союз, 1997. 256 с.

6. Филичева Т. Б., Чевелева Н. А., Чиркина Г. В. Основы логопедии. М.: Просвещение, 1989. 223 с.

7. Смирнова О. А., Холмогорова В. М. Межличностные отношения дошкольников: диагностика, проблемы, коррекция. М.: Владос, 2005. $158 \mathrm{c}$.

8. Репина М. А., Мухина Т. К. Особенности межличностных отношений детей дошкольного возраста // Молодой ученый. 2015 . № 9. C. 1267-1269. URL: https://moluch.ru/archive/89/17742/ (дата обращения: 27.03.2018).

9. Poteat M., Ironsmith M., Bullock J. The classification of preschool children's sociometric status // Early Childhood Research Quarterly. 1986. Vol. 1, Iss. 4. P. 349-360. URL: https://doi.org/10.1016/0885-2006(86)90012-8.

10. Nelson D., Burner K., Coyne S., Hart C., Robinson C. Correlates of sociometric status in Russian preschoolers: Aggression, victimization, and sociability // Personality and Individual Differences. 2016. Vol. 94. May. P. 332-336. URL: https://doi.org/10.1016/j.paid.2016.01.054.

11. Колосовская А. В. Обогащение мотивов речевой деятельности детей старшего дошкольного возраста в процессе обучения: дис. ... канд. пед. наук. М., 1999. 188 с.

12. Крутий Е. Речепассивные дошкольники: к проблеме терминологического определения // Проблемы развития речи дошкольников и подготовка специалистов в условиях модернизации образования / под ред. О. С. Ушаковой, В. И. Яшиной. М., 2004. С. 44-45.

13. Ушакова О. С. Развитие речи дошкольников. М.: Институт психотерапии, 2001. 264 с.

14. Горецкий В. Г., Кирюшкин В. А., Федосова Н. А. Методическое пособие по обучению грамоте и письму. М.: Просвещение, 2004.128 с.

15. Алексеева М. М., Яшина Б. И. Методика развития речи и обучения родному языку дошкольников. М.: Академия, 2000.400 с.

16. Ладыженская Т. А., Тамбовкина Т. И. Особенности развития связной речи детей младшего школьного возраста // Характеристика связной речи детей младшего школьного возраста. М., 1981. С. 4-24.

17. Красильникова Л. В. Многоуровневая технология развития осознанной речевой активности детей младшего дошкольного возраста: дис. ... канд. пед. наук. Н. Новгород, 2008. 238 с.

18. Коломинский Я. Л. Психология взаимоотношений в малых группах (общие и возрастные особенности). Минск: ТетраСистемс, 2000. $432 \mathrm{c}$.

Пронина Анжелика Николаевна, доктор педагогических наук, доцент, Елецкий государственный университет им. И. А. Бунина (ул. Коммунаров, 28, Липецкая область, Елец, Россия, 399770). E-mail: antipi-elena@yandex.ru

Яковлева Ирина Васильевна, старший преподаватель, Елецкий государственный университет им. И. А. Бунина (ул. Коммунаров, 28, Липецкая область, Елец, Россия, 399770). E-mail: yakovlevairinavas070882@mail.ru

DOI 10.23951/1609-624X-2018-7-96-102

\section{CHARACTERISTICS OF SPEECH ACTIVITY OF OLDER PRESCHOOLERS WITH DIFFERENT SOCIOMETRIC STATUS}

\author{
A. N. Pronina, I. V. Yakovleva
}

Yelets State Bunin University, Lipetsk region, Yelets, Russian Federation

The relevance of this study is due to the fact that the high level of speech activity ensures the establishment of positive interpersonal relationships of preschoolers with peers and the child's occupation of a certain status position in the children's collective. The author raises the question of comparative characteristics of speech activity of preschool children with different sociometric statuses. The article describes the criteria, indicators and levels of speech activity of preschool children, which are used in the organization of observations of children of different sociometric statuses in free play and organized joint activities. In particular, such criteria of speech activity as initiative, type of speech communication, speech motivation, content and emotional expressiveness are highlighted. The results of the experiment, for example, revealed a high level of speech activity in children with the status of "stars", the middle and low level of speech. The detailed description of levels and characteristics of speech activity of preschool children with different sociometric statuses is given. Statistics of comparison of criteria, levels of speech activity of children with different sociometric statuses and explanation of such differences are presented. Thus, the study revealed differences 
between children with the status of "stars" and "isolated" according to the criteria of speech initiative, motivation and types of speech communication.

Key words: speech, activity, speech activity, socialization, interpersonal relations, sociometric status, preschool children, influence, group of peers.

\section{References}

1. Vygotskiy L. S. Sobraniye sochineniy: $v 6$ t. T. 4 Detskaya psikhologiya [Collected works: in 6 volumes. V. 4: Child psychology]. Ed. by D. B. Elkonin. Moscow, Pedagogika Publ., 1984. 432 p. (in Russian).

2. Zimnyaya I. A. Psikhologiya obucheniya nerodnomu yazyku [Psychology of teaching non-native language]. Moscow, Russkiy yazyk Publ., 1989. Pp. 14-15 (in Russian).

3. Leont'ev A. A. Osnovy psikholingvistiki [Fundamentals of psycholinguistics]. Moscow, Smysl Publ., 1997. P. 19 (in Russian).

4. Shakhnarovich A. M. Detskaya rech' v zerkale psikholingvistiki [Children's speech in the mirror of psycholinguistics]. Moscow, IAS Academy of Sciences Publ., 1999. P. 34-36 (in Russian).

5. Piazhe Zh. Rech'i myshleniye rebenka [Speech and thinking of the child]. Saint Petersburg, Soyuz Publ., 1997. 256 p. (in Russian).

6. Filicheva T. B., Cheveleva N. A., Chirkina G. V. Osnovy logopedii [Fundamentals of speech therapy]. Moscow, Prosveshcheniye Publ., 1989. 223 p. (in Russian).

7. Smirnova O. A., Kholmogorova V. M. Mezhlichnostnyye otnosheniya doshkol'nikov: diagnostika, problemy, korrektsiya [Interpersonal relationships of preschoolers: diagnosis, problems, correction]. Moscow, Vlados Publ., 2005. 158 p. (in Russian).

8. Repina M. A., Mukhina T. K. Osobennosti mezhlichnostnykh otnosheniy detey doshkol'nogo vozrasta [Features of interpersonal relations of preschool children]. Molodoy uchenyy, 2015, no. 9, pp. 1267-1269 (in Russian). URL: https://moluch.ru/archive/89/17742/ (accessed 27 March 2018).

9. Poteat M., Ironsmith M., Bullock J. The classification of preschool children's sociometric status. Early Childhood Research Quarterly, 1986, vol. 1, iss. 4, pp. 349-360. URL: https://doi.org/10.1016/0885-2006(86)90012-8

10. Nelson D., Burner K., Coyne S., Hart C., Robinson C. Correlates of sociometric status in Russian preschoolers: Aggression, victimization, and sociability. Personality and Individual Differences, 2016, vol. 94, pp. 332-336. URL:https://doi.org/10.1016/j.paid.2016.01.054.

11. Kolosovskaya A.B. Obogashcheniye motivov rechevoy deyatel'nosti detey starshego doshkol'nogo vozrasta v protsesse obucheniya. Dis. kand. ped. nauk [Enrichment of motives of speech activity of preschool children in the learning process. Diss. cand. ped. sci.]. Moscow, 1999. 188 p. (in Russian).

12. Krutiy E. Rechepassivnyye doshkol'niki: $k$ probleme terminologicheskogo opredeleniya [Speech passive pre-schoolers: to the problem of terminology definition]. Problemy razvitiya rechi doshkol'nikov i podgotovka spetsialistov v usloviyakh modernizatsii obrazovaniya [Problems of speech development of preschoolers and training of specialists in the context of the modernization of education]. Ed. by O. S. Ushakova, V. I. Yashina. Moscow, 2004. Pp. 44-45 (in Russian).

13. Ushakova O. S. Razvitiye rechi doshkol'nikov [The development of speech of preschool children]. Moscow, Institute of Psychotherapy Publ., 2001. 264 p. (in Russian).

14. Goretskiy V. G., Kiryushkin V. A., Fedosova N. A. Metodicheskoye posobiye po obucheniyu gramote i pis'mu [Manual for teaching literacy and writing]. Moscow, Prosveshcheniye Publ., 2004. 128 p. (in Russian).

15. Alekseeva M. M., Yashina B. I. Metodika razvitiya rechi i obucheniya rodnomu yazyku doshkol'nikov [Methodology of speech development and teaching of preschool children's native language]. Moscow, Akademiya Publ., 2000. 400 p. (in Russian).

16. Ladyzhenskaya T. A., Tambovkina T. I. Osobennosti razvitiya svyaznoy rechi detey mladshego shkol'nogo vozrasta [Features of development of coherent speech of children of younger school age]. Kharakteristika svyaznoy rechi detey mladshego shkol'nogo vozrasta [Characteristics of coherent speech of children of primary school age]. Moscow, 1981. Pp. 4-24 (in Russian).

17. Krasil'nikova L. V. Mnogourovnevaya tekhnologiya razvitiya osoznannoy rechevoy aktivnosti detey mladshego doshkol'nogo vozrasta. Dis. kand. ped. nauk [Multilevel technology of development of conscious speech activity of children of preschool age. Diss. cand. ped. sci.]. Nizhniy Novgorod, 2008. 238 p. (in Russian).

18. Kolominskiy Ya. L. Psikhologiya vzaimootnosheniy v malykh gruppakh (obshchiye $i$ vozrastnyye osobennosti) [Psychology of relationships in small groups (General and age features)]. Minsk, Tetrasystems Publ., 2000. 432 p. (in Russian).

Pronina A. N., Yelets State Bunin University (ul. Kommunarov, 28, Yelets, Russian Federation, 399770). E-mail: antipi-elena@yandex.ru

Yakovleva I. V., Yelets State Bunin University (ul. Kommunarov, 28, Yelets, Russian Federation, 399770).

E-mail: yakovlevairinavas070882@mail.ru 